\title{
FEIRA DE CIÊNCIAS DO ESTADO DE ALAGOAS: CONQUISTAS E DESAFIOS NO DESENVOLVIMENTO DOS TRABALHOS
}

\author{
ALAGOAS STATE SCIENCE FAIR: \\ ACHIEVEMENTS AND CHALLENGES IN WORK DEVELOPMENT \\ FERIA ESTATAL DE CIENCIAS DE ALAGOAS: \\ LOGROS Y RETOS EN EL DESARROLLO LABORAL
}

Bibiane de Fátima Santos ${ }^{1}$ (D) 0

Maria Danielle Araújo Mota² (D) 9

Paulo Meireles Barguil ${ }^{3}$ (D) $(9$

\begin{abstract}
RESUMO
Nas últimas décadas, inúmeros trabalhos relatam a contribuição das Feiras de Ciências e dos Museus de Ciências na divulgação científica, elencando possibilidades, conquistas e desafios. Embora diversos autores relatem a importância das Feiras de Ciências na divulgação do conhecimento científico, no ambiente escolar e na sociedade, é necessário admitir que elas possuem limitações na realização e/ou na exposição dos trabalhos. Essa pesquisa teve como objetivo analisar como foram desenvolvidos os trabalhos apresentados na Feira de Ciências do Estado de Alagoas (FECEAL) em 2019, pois conhecer as escolhas, os desafios e as conquistas que os estudantes vivenciam na realização dos trabalhos pode contribuir para ampliar as aprendizagens dos participantes - estudantes e visitantes - das Feiras de Ciências. Foi realizada uma pesquisa qualitativa, mediante questionário, com 41 (quarenta e um) estudantes de escolas públicas do estado de Alagoas, que apresentaram trabalho na FECEAL 2019. O questionário continha 7 (sete) perguntas sobre: o tipo de trabalho, o motivo da participação, o processo de escolha do tema, o local, a metodologia, o alcance dos objetivos e o tipo de auxílio recebido. Os dados colhidos ratificam que a Feira de Ciência pode favorecer a produção e divulgação científica, melhorando a aprendizagem discente, bem como o vínculo entre escola e sociedade. Identificamos limites no desenvolvimento dos trabalhos apresentados na FECEAL 2019, de modo especial, no tipo de trabalho e na metodologia. Para enfrentar esses desafios, é necessário o apoio dos órgãos competentes para melhorar as condições de trabalho docente, a formação continuada e a infraestrutura.
\end{abstract}

Palavras-chave: Feira de Ciências. Ensino e Aprendizagem de Ciências e Biologia. Projetos de Ciências. Divulgação científica. Educação Não-Formal.

\begin{tabular}{l}
${ }^{1}$ Licencianda em Ciências Biológicas pela Universidade Federal de Alagoas (UFAL). Bolsista de Iniciação \\
Científica da Universidade Federal de Alagoas (UFAL), Maceió, Alagoas, Brasil. Endereço para \\
correspondência: Rua Francisco Alves, 278, $1^{\circ}$ andar, Santa Lúcia, Maceió, Alagoas, Brasil, CEP: 57.082-140. \\
E-mail: bibiane.santos@icbs.ufal.br. \\
${ }^{2}$ Doutora em Educação pela Universidade Federal do Ceará (UFC). Professora Adjunta I da Universidade Federal \\
de Alagoas (UFAL), Maceió, Alagoas, Brasil. Endereço para correspondência: Av. Dr. Milton Hênio Netto de \\
Gouveia, 406, Condomínio Parque das Galés, apto. 107, Antares, Maceió, Alagoas, Brasil, CEP: 57.083-410. E- \\
mail: danielle.araujo@,icbs.ufal.br. \\
${ }^{3}$ Doutor em Educação pela Universidade Federal do Ceará (UFC). Professor Associado IV da Universidade \\
Federal do Ceará (UFC), Fortaleza, Ceará, Brasil. Endereço para correspondência: Alameda Santa Lúcia, 286, \\
Alphaville Ceará 2, Cidade Nova, Eusébio, Ceará, Brasil, CEP: 61.760-911. E-mail: paulobarguil@ufc.br. \\
\hline
\end{tabular} 


\begin{abstract}
In the last decades, countless works report the contribution of Science Fairs and Science Museums in scientific dissemination, listing possibilities, achievements and challenges. Although several authors report the importance of Science Fairs in the dissemination of scientific knowledge, in the school environment and in society, it is necessary to admit that they have limitations in carrying out and/or exhibiting works. This research aimed to analyze how the works presented at the Science Fair of the State of Alagoas (FECEAL) were developed in 2019, as knowing the choices, challenges and achievements that students experience in carrying out the work can contribute to expand learning of participants - students and visitors - from Science Fairs. A qualitative research was carried out, through a questionnaire, with 41 (forty-one) students from public schools in the state of Alagoas, who presented work at FECEAL 2019. The questionnaire contained 7 (seven) questions about: the type of work, the reason for participation, the process of choosing the theme, the location, the methodology, the achievement of the objectives and the type of assistance received. The data collected confirm that the Science Fair can favor scientific production and dissemination, improving student learning, as well as the link between school and society. We identified limits in the development of the works presented at FECEAL 2019, especially in the type of work and the methodology. In order to face these challenges, the support of Organs competent bodies is necessary to improve teaching working conditions, continuing education and infrastructure.
\end{abstract}

Keywords: Science fair. Teaching and Learning Science and Biology. Science Projects. Scientific Divulgation. Non-Formal Education.

\title{
RESUMEN
}

En las últimas décadas, innumerables trabajos reportan la contribución de las Ferias de Ciencias y los Museos de la Ciencia en la divulgación científica, enumerando posibilidades, logros y desafíos. Si bien varios autores señalan la importancia de las Ferias de Ciencias en la difusión del conocimiento científico, en el ámbito escolar y en la sociedad, es necesario admitir que tienen limitaciones para realizar y/o exhibir trabajos. Esta investigación tuvo como objetivo analizar cómo se desarrollaron los trabajos presentados en la Feria de Ciencias del Estado de Alagoas (FECEAL) en 2019, pues conocer las opciones, desafíos y logros que experimentan los estudiantes en la realización del trabajo puede contribuir a ampliar el aprendizaje. de participantes - estudiantes y visitantes - de Ferias de Ciencias. Se realizó una investigación cualitativa, a través de un cuestionario, con 41 (cuarenta y un) estudiantes de escuelas públicas del estado de Alagoas, quienes presentaron trabajos en FECEAL 2019. El cuestionario contenía 7 (siete) preguntas sobre: el tipo de trabajo, el motivo de participación, el proceso de elección de la temática, la ubicación, la metodología, el logro de los objetivos y el tipo de asistencia recibida. Los datos recogidos confirman que la Feria de las Ciencias puede favorecer la producción y difusión científica, mejorando el aprendizaje de los alumnos, así como el vínculo entre escuela y sociedad. Identificamos límites en el desarrollo de los trabajos presentados en FECEAL 2019, especialmente en el tipo de trabajo y la metodología. Para hacer frente a estos desafíos, es necesario el apoyo de los órganos competentes para mejorar las condiciones de trabajo docente, la formación continua y la infraestructura.

Palabras clave: Feria de Ciencias. Enseñanza y Aprendizaje de la Ciencia y la Biología. Proyectos de Ciencia. Divulgación Científica. Educación No Formal. 


\section{INTRODUÇÃO}

A aprendizagem de cada pessoa é fruto das suas interações em espaços-tempos múltiplos. Considerando a intencionalidade, a organização curricular e a legislação, a Educação pode ser formal, informal e não-formal ${ }^{4}$.

A Educação formal obedece a uma legislação, acontece em escolas (Educação Básica) e universidades (Educação Superior), e possui algumas características: intencionalidade, agentes pedagógicos (professor e estudantes), currículo, material didático, avaliação, progressividade, dentre outras. A Educação informal acontece no cotidiano, na convivência com a família e amigos, em clubes, igrejas e praças. A sua principal característica é a não intencionalidade, a espontaneidade dos vínculos.

A Educação não-formal se situa entre as anteriores, contemplando conteúdos variados, que podem ser ou não contemplados na Educação formal, mediante práticas que podem ter ou não intencionalidade. Gaspar (2002) lista os seguintes exemplos: cursos de línguas estrangeiras e de especialidades artísticas ou técnicas, oferecidos presencialmente ou à distância, com horários que podem ser rígidos ou flexíveis. Também estão nessa categoria as experiências proporcionadas, comumente via exposição, por espaços específicos: centros culturais, jardins botânicos, museus de arte ou de ciências, zoológicos.

Nas últimas décadas, inúmeros trabalhos, dos quais alguns serão comentados neste texto, relatam a contribuição das Feiras de Ciências e dos Museus de Ciências na divulgação científica, elencando possibilidades, conquistas e desafios. Este artigo aborda aspectos pertinentes às Feiras de Ciências.

Apesar de elas serem bastante populares, há muitos estudantes que nunca as vivenciaram. Mas o que é uma Feira de Ciências?

\footnotetext{
A Feira de Ciências é um empreendimento técnico-científico-cultural que se destina a estabelecer o inter-relacionamento entre a escola e a comunidade. Oportuniza aos alunos demonstrarem, por meio de projetos planejados e executados por eles, a sua criatividade, o seu raciocínio lógico, a sua capacidade de pesquisa e seus conhecimentos científicos. (MORAES, 1986, p. 20).
}

\footnotetext{
4 “ [...] educação escolar formal desenvolvida nas escolas; educação informal [...] decorre de processos naturais e espontâneos; e educação não-formal, [...] quando existe a intenção de determinados sujeitos em criar ou buscar determinados objetivos fora da instituição escolar. [a educação não-formal] proporciona a aprendizagem de conteúdos da escolarização formal em espaços como museus, centros de ciências, ou qualquer outro em que as atividades sejam desenvolvidas [...] com um objetivo definido.”. (VIEIRA; BIANCONI; DIAS, 2005, p. 21). 
Feiras de Ciências são eventos sociais, científicos e culturais realizados nas escolas ou na comunidade com a intenção de, durante a apresentação dos estudantes, oportunizar um diálogo com os visitantes, constituindo-se na oportunidade de discussão sobre os conhecimentos, metodologias de pesquisa e criatividade dos alunos em todos os aspectos referentes à exibição dos trabalhos. (MANCUSO, 2006).

A Feira de Ciência estimula, organiza e divulga a produção científica da escola. Anima alunos, professores e famílias e, quando incorporada ao currículo, resulta numa estratégia educacional que naturalmente estimula atividades de investigação científica na escola, favorecendo o ensino de ciências 'fazendo ciência' (PAVÃO, 2008). (PAVÃO; LIMA, 2019, p. 03).

Nas Feiras de Ciências, os estudantes apresentam seus projetos de Ciências (objetivos, metodologia, resultados e conclusões), desenvolvidos sob a orientação docente, para estudantes, professores e a comunidade, sendo, ao mesmo tempo, resultado de uma Educação formal e um importante espaço de Educação não-formal (CORSINI; ARAÚJO, 2007).

Embora diversos autores relatem a importância das Feiras de Ciências na divulgação científica, no ambiente escolar e na sociedade, é necessário admitir que elas possuem limitações na realização e/ou na exposição, as quais precisam ser conhecidas para que contribuam, cada vez mais, para a produção e a propagação das Ciências.

A Feira de Ciências do Estado de Alagoas (FECEAL) ${ }^{5}$ é um evento anual, promovido pela Secretaria de Educação (SEDUC) do estado de Alagoas, que possui em 3 níveis: escola, região e estado. Os trabalhos aprovados nas escolas são apresentados em feiras nas 13 (treze) Gerências Regionais de Ensino da SEDUC/AL, que congregam vários municípios, quando são selecionados os que irão para o nível 3, que acontece em Maceió.

Uma Feira de Ciência pode ter várias configurações, motivo pelo qual a sua dinâmica e os seus trabalhos possuem características singulares, de acordo com a proposta daquela. Em relação à FECEAL, indagávamo-nos: Quais foram as motivações discentes para desenvolver os trabalhos? Como aconteceu a escolha do tema? Onde as atividades foram realizadas? Que metodologia foi utilizada? Os objetivos foram alcançados? Quem apoiou os estudantes na realização dos trabalhos?

\footnotetext{
${ }^{5}$ Os objetivos da FECEAL são: Incentivar a construção de atividades de iniciação científica na Educação Básica, visando o conhecimento científico e pedagógico; Motivar professores e estudantes para o uso efetivo dos kits de laboratórios de Ciências a Natureza e de Matemática existentes nas escolas estaduais; Incentivar a pesquisa nos componentes curriculares que integram as áreas de Ciências da Natureza e da Matemática; Socializar a produção dos estudantes da Educação Básica, como incentivo à pesquisa científica e pedagógica; Promover entre professores e estudantes a cultura da Feira de Ciências; Proporcionar a elaboração e o desenvolvimento de projetos interdisciplinares; Proporcionar maior integração entre as escolas e a comunidade escolar. (ALAGOAS, 2016). A $1^{\text {a }}$ Edição aconteceu em 2013. As informações da FECEAL 2019 estão na metodologia.
} 
Essa pesquisa teve como objetivo analisar como os trabalhos de Ciências apresentados na Feira de Ciências do Estado de Alagoas (FECEAL) em 2019 foram desenvolvidos, pois conhecer as escolhas, os desafios e as conquistas que os estudantes vivenciam na realização dos trabalhos pode contribuir para que se possa, continuamente, ampliar as aprendizagens para os participantes - estudantes e visitantes - das Feiras de Ciências.

Nas próximas seções, apresentaremos o referencial teórico, a metodologia, os resultados e as análises, concluindo com as considerações finais.

\section{REFERENCIAL TEÓRICO}

A Feira de Ciências surgiu, em 1930, nos Estados Unidos, tendo chegado no o Brasil em 1960, e objetivava “[...] familiarizar os estudantes e a comunidade escolar com os materiais existentes nos laboratórios, antes quase inacessíveis e, portanto, desconhecidos na prática pedagógica.” (MANCUSO, 2000, p. 01).

Uma compreensão equivocada da palavra Ciências, no contexto da produção do conhecimento e das Feiras de Ciências, limita-a apenas às disciplinas Biologia, Física, Matemática e Química. Nós a entendemos “[...] no seu sentido mais amplo, referindo-se muito mais à 'pesquisa científica em qualquer ciência', o que pode (e deve) ocorrer em todos os campos do conhecimento.”. (BRASIL, 2006, p. 17).

Esse também é entendimento de Pereira, Oaigen e Hennig (2000), quando afirmam que as Ciências da Natureza e suas Tecnologias apresentam grande potencialidade de melhoria do ensino visando ao desenvolvimento científico e tecnológico do país. Mas isso não quer dizer que as outras áreas, como as Ciências Humanas e suas tecnologias, não possam participar de uma Feira de Ciências, pois o conjunto de experiências multidisciplinares complementa o ensino formal.

Ademais, não concordamos com a crença de que a Humanidade só produz conhecimento quando segue os passos do método científico tradicional (problema, hipóteses, dedução, testagem, conclusão), pois os procedimentos investigativos, que compõem a pesquisa, precisam considerar o que se pretende compreender.

Pesquisa significa "[...] procurar; buscar com cuidado; procurar por toda a parte; informar-se; inquirir, perguntar; indagar bem, aprofundar na busca." (BAGNO, 1998, p. 17). Ela designa, também, um processo em que estudantes, com a orientação de professores, se 
envolvem com o intuito de construírem, durante a busca de informações, “[...] juntos um conhecimento que lhes é próprio.” (FARIAS; GONÇALVES, 2007, p. 26).

Concordamos com Falcão Sobrinho, Falcão e Almeida (2014, p. 110), quando afirmam que "[...] as feiras de ciências e mostras científicas despertam vocação científica dos alunos da educação básica, mediante participação em projeto de pesquisa e sob orientação de profissional qualificado.”.

Conforme Farias e Gonçalves (2007, p. 26),

As Feiras de Ciências podem ser utilizadas para repetição de experiências realizadas em sala de aula; montagem de exposições com fins demonstrativos; como estímulo para aprofundar estudos e busca de novos conhecimentos; oportunidade de proximidade com a comunidade científica; espaço para iniciação científica; desenvolvimento do espírito criativo; discussão de problemas sociais e integração escola-sociedade.

Embora as Feiras de Ciências aproximem o estudante da Educação Básica do conhecimento científico, enriquecendo os processos de ensino e de aprendizagem e apresentando resultados bastante promissores, elas são realizadas com pouca frequência (COSTA; ROEHRS; DESTRO; GIMENEZ; MELLO, 2018).

Conforme Machado, Blanco, Barros e Cardoso (2014, p. 03), a Feira de Ciências

[...] é uma ferramenta primordial para a educação por possibilitar ao estudante um primeiro contato com a criação, o desenvolvimento e a apresentação de um projeto de pesquisa e, por conseguinte, desenvolver diversas habilidades não trabalhadas em um ambiente normal de sala de aula.

Cabral e Barroso (2020, p. 03) enfatizam a importância do apoio do poder público para a realização Feiras de Ciências em prol de uma Educação de qualidade, pois acreditam que elas “[...] se inscrevem dentro desse novo circuito como espaço e oportunidade privilegiada no campo educacional de iniciação a pesquisa e do desenvolvimento criativo, ao mesmo tempo em que consolida a alfabetização científica no chão da escola.”.

Conforme Castro, Araújo e Oliveira (2019, p. 180), “As Feiras de Ciências podem ser consideradas um espaço múltiplo, com elevado potencial para promover aprendizagens, tanto para os estudantes e professores-orientadores quanto para o coletivo escolar e a comunidade em geral.".

Embora as possibilidades de ensino e de aprendizagem nas Feiras de Ciências sejam muitas, Mancuso (2000) alerta que a realização da Feira de Ciências não é garantia de uma 
Educação Científica de qualidade na Educação Básica, pois ainda há muitos trabalhos demonstrativos e repetições de livros didáticos ou de experiências realizadas pelo professor.

Farias e Gonçalves (2007) relatam uma situação em que a ação docente se limitou na escolha do experimento de um livro e na solicitação para que os estudantes o reproduzissem e apresentassem na Feira de Ciências. Essa conduta pedagógica - característica de uma Educação tradicional, a qual acredita que o conhecimento pode ser transmitido, sem interação e questionamentos - não possibilita que os discentes expressem seus interesses e mobilizem suas curiosidades, aspectos indispensáveis para que aconteça a aprendizagem.

Fazemos coro a Severino (2016, p. 25-26), quando afirma que "[...] aprender por meio da investigação e da descoberta autônoma, pode gerar uma aprendizagem com resultados mais significativos e importantes para o percurso acadêmico dos estudantes.", motivo pelo qual acreditamos que o desenvolvimento de projetos de Ciências é uma estratégia poderosa que precisa ser, cada vez mais, incorporada no cotidiano da Educação Básica, sendo necessário cuidado para não perpetuar o modelo educacional tradicional baseado na repetição.

Apesar dos vários pontos positivos que a Feira de Ciência pode proporcionar, Weber (2016, p. 188) afirma que muitas escolas públicas “[...] sequer possuem laboratórios de ciências ou materiais em condições de uso.", e alerta para a falta de senso investigativo nas escolas, pois os estudantes não costumam pesquisar, investigar e elaborar hipóteses.

Em prol de um maior engajamento discente, é importante que a elaboração e o desenvolvimento dos projetos aconteçam a partir de problemas da comunidade, os quais favorecem a realização de trabalhos inéditos (NEVES; GONÇALVES, 1989). Esta ideia se articula com a opinião de Costa et al (2018), quando dizem que temas considerados relevantes pelos estudantes no seu cotidiano poderão conduzi-los a elevados níveis de aprendizagem.

Para que o protagonismo estudantil aconteça e possibilite aprendizagens múltiplas, além da cognitiva, é necessário que o professor adote metodologias que favoreçam a participação discente e o desenvolvimento da crítica, da curiosidade. Em relação a isso, Ramos, Lima e Rocha Filho (2009, p. 56) declaram:

Quando a sala de aula se torna um ambiente de investigação, além de construir conhecimentos de maneira independente participando intensamente do processo, os atores exercitam e fortalecem valores, tendo em vista que eles são, ainda, incentivados a trabalhar atitudes de respeito e diálogo, num exercício de construção de cidadania.

A Feira de Ciências pode ser realizada por escolas ou outra entidade do campo educacional com a intenção de, durante a exposição dos trabalhos, proporcionar, dentre várias 
contribuições, um diálogo com os visitantes sobre os conhecimentos, as metodologias de pesquisa e a criatividade dos estudantes envolvidos (FARIAS; GONÇALVES, 2007).

Conforme Corsini e Araújo (2007), a exposição em uma Feira de Ciências pode contribuir para o desenvolvimento cognitivo dos estudantes, professores e da comunidade visitante, complementando a Educação escolar dos discentes e enriquecendo a Educação Científica, tanto para esses como para a população.

Além dos aspectos cognitivos, o que podem aprender os estudantes participantes de uma Feira de Ciências? Mancuso (2000, p. 03) listou alguns benefícios:

Crescimento pessoal e ampliação das vivências e conhecimentos; ampliação da capacidade comunicativa; mudanças de hábitos e atitudes; desenvolvimento da criticidade e da capacidade de avaliação; maior envolvimento, motivação e interesse; exercício da criatividade com a apresentação de inovações; politização, principalmente, pela formação de lideranças e visão de mundo.

Montes e Souza (2008, p. 64), por sua vez, afirmam que os estudantes, quando participam em eventos não formais, como uma Feira de Ciências, além de se sentirem motivados, percebem que podem aprender ensinando e não só ao aprenderem, o que pode colaborar "[...] para que deixemos de ter um ensino exclusivamente memorístico permitindo uma melhora no nível de eficiência do processo de aprendizagem.”.

Concordamos com Strohschoen, Puhl e Marchi (2013, p. 44), quando listam benefícios na participação de estudantes em Feira de Ciências: “[...] mudanças de hábitos e atitudes; desenvolvimento da criticidade e da capacidade de avaliação; maior envolvimento, motivação e interesse; exercício da criatividade com a apresentação de inovações.”.

Os projetos apresentados nas Feiras de Ciências, portanto, podem contribuir tanto para o desenvolvimento discente em várias dimensões, não somente a cognitiva, quanto para uma maior integração escola-comunidade, além de favorecer a divulgação científica mediante Educação Não-Formal. É necessário, contudo, atentar para alguns aspectos que caracterizam o desenvolvimento dos trabalhos e influenciam na materialização do potencial das Feiras de Ciências: motivação discente, escolha do tema, metodologia, exposição, dentre outros.

\section{METODOLOGIA}

Para este trabalho, foi realizada uma pesquisa qualitativa, cujo foco é o processo e não somente os resultados (LÜDKE; ANDRÉ, 1986). Ele também é um estudo de caráter descritivo, 
pois há o interesse em traçar “[...] com exatidão os fatos e fenômenos de determinada realidade." (TRIVIÑOS, 1987, p. 110).

Os sujeitos dessa pesquisa foram 41 estudantes $^{6}$, de idades entre 13 anos e 17 anos, dos anos finais do Ensino Fundamental e do Ensino Médio, de 20 escolas públicas do estado de Alagoas, que apresentaram seus trabalhos na Feira de Ciências do Estado de Alagoas (FECEAL), em $2019^{7}$.

A seleção dos sujeitos aconteceu após os responsáveis avaliarem os trabalhos nas mesas de apresentações, tendo a pesquisadora exposto, inicialmente ao professor, a sua pesquisa e o seu objetivo. Caso houvesse concordância dele, o processo se repetia com os estudantes, os quais eram convidados a participar da investigação.

Além disso, houve a assinatura do Termo de Consentimento Livre e Esclarecido dos professores responsáveis destes discentes, ressaltando que a qualquer momento poderiam se recusar ou desistir da participação na pesquisa, porém nenhum dos convidados repeliu.

Para a coleta de dados, foi adotado o questionário estruturado, o qual, conforme Gil (1999, p. 128), é uma “[...]a técnica de investigação composta por questões apresentadas por escrito às pessoas, tendo por objetivo o conhecimento de opiniões, crenças, sentimentos, interesses, expectativas, situações vivenciadas etc.”.

Optamos pelo uso do questionário porque ele, conforme Gil (1999), possibilita que os participantes respondam com maior liberdade de pensamento e tempo, como também há a possibilidade de atingir um grande número de pessoas, mesmo que estejam dispersas em área geográfica extensa, que era o caso deste trabalho. O questionário tinha 7 (sete) questões: 4 (quatro) subjetivas $-2,3,5$ e 6 - e 3 (três) objetivas - 1, 4 e 7. As questões subjetivas possibilitavam que os participantes respondessem conforme sua própria experiência.

Os dados coletados nas respostas discentes foram interpretados e analisados à luz das contribuições teóricas expostas e da nossa experiência acadêmica e profissional.

\section{RESULTADOS E ANÁLISES}

Nessa seção, as respostas dos estudantes participantes às indagações do questionário serão apresentadas e discutidas.

\footnotetext{
${ }^{6}$ A identidade dos estudantes foi preservada, sendo estes identificados como P01, P02, P03... P41.

${ }^{7} \mathrm{Na}$ FECEAL 2019, foram apresentados 98 (noventa e oito) trabalhos, de 61 (sessenta e uma) escolas públicas de Alagoas, divididos nas seguintes categorias: Astronomia (07 trabalhos); Biologia (18 trabalhos); Ciências da Natureza (04 trabalhos); Ciências Humanas (15 trabalhos); Engenharia, Inovação \& Tecnologia (09 trabalhos), Física (10 trabalhos), Matemática (03 trabalhos) e Química (32 trabalhos). As apresentações aconteciam em duplas, com estudantes, ou em trios, com estudantes e o(a) professor(a) orientador(a). 
A primeira pergunta se referia sobre o tipo do trabalho, os quais, conforme Mancuso (2000), podem ser: de montagem, informativo e investigatório. Dentre as 41 (quarenta e uma) respostas, 30 (trinta) foram do tipo Investigatório (Figura 1). Os tipos Informativo e Montagem receberam 4 (quatro) marcações cada, além da opção "Outros” ter sido indicada por 3 (três) estudantes, que não a especificaram.

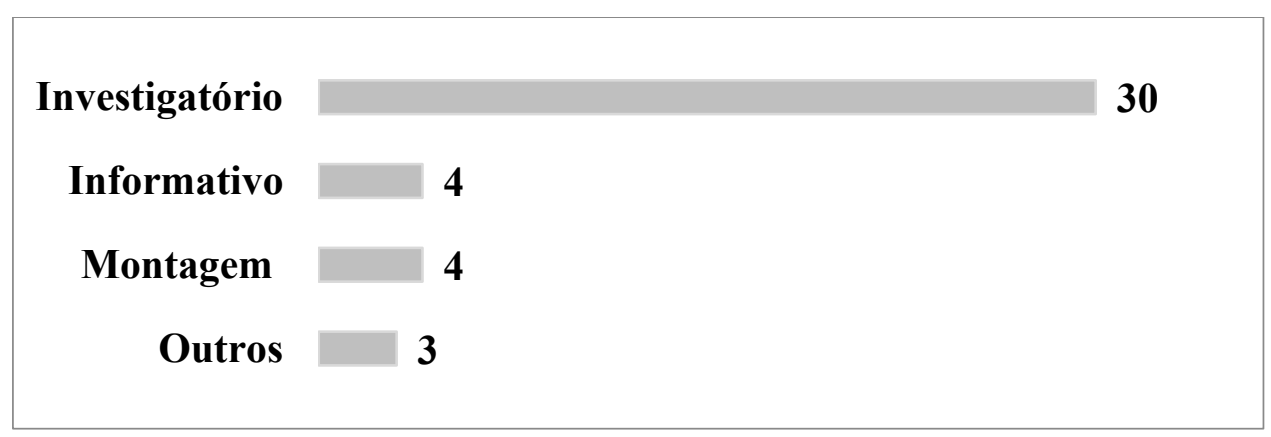

Figura 1 - Tipos dos trabalhos apresentados na FECEAL 2019 Fonte: Pesquisa dos autores.

Conforme Weber (2016, p. 01), em muitas escolas, há falta de senso investigativo e os estudantes “[...] não estão acostumados a pesquisar, a investigar e a levantar hipótese.”. A quantidade expressiva de respostas dos estudantes no tipo Investigatório pode indicar que os projetos de Ciências estão contribuindo para suprir as lacunas apontadas pela autora, bem como para propiciar que os estudantes ampliem seu interesse e sua curiosidade pelas Ciências.

A atitude investigativa, problematizadora, questionadora da realidade é indispensável na produção do conhecimento, pois esse sempre pode ser ampliado, modificado. Isso também é verdadeiro na área de Ciências da Natureza: o conhecimento científico não está acabado e sim que é construído por meio de pesquisas.

O trabalho do tipo Informativo objetiva demonstrar algum fenômeno científico, sendo utilizado para favorecer a compreensão dos conteúdos escolares. O trabalho do tipo Investigatório, por sua vez, estimula a aprendizagem do estudante ao não conhecido.

Os resultados que encontramos $-73 \%$ investigatório, $10 \%$ informativo, $10 \%$ montagem e 7\% outro - diferem dos relatados por Santos (2012): 50\% informativo, 33\% montagem e 17\% investigação. Essa discrepância indica a necessidade de não considerar apenas o que é declarado pelos estudantes, mas de avaliar o trabalho apresentado.

A participação dos estudantes da Educação Básica em projetos de Ciências favorece que eles, ao mesmo tempo, aprendam conteúdos relacionados ao tema escolhido e desenvolvam comportamentos e habilidades características de cientistas. O trabalho do tipo Informativo 
demonstra algum fenômeno científico, sendo utilizado para favorecer a compreensão dos conteúdos escolares. O trabalho do tipo Investigatório, por sua vez, estimula a aprendizagem do estudante ao não conhecido.

Embora saibamos dessa diferença qualitativa nos tipos de trabalho, acreditamos que, independentemente do tipo do trabalho, o estudante participante "[...] acaba sendo inserido no universo da pesquisa científica, fomentando habilidades para o desenvolvimento da cultura científica." (STROHSCHOEN et al, 2013, p. 44).

Quando questionados sobre o motivo da sua inscrição no evento, o mais citado, com 23 (vinte e três) respostas (Figura 2), foi a divulgação científica, exemplificado com a fala de P07: "Porque eu gostaria de repassar mais conhecimento para a sociedade.". Esse depoimento confirma que as Feiras de Ciências "[...] podem proporcionar que os estudantes exponham trabalhos por eles realizados à comunidade, possibilitando um intercâmbio de informações." (PEREIRA et al, 2000, p. 38), e, consequentemente, favorecendo a divulgação do conhecimento científico.

As Feiras de Ciências possuem um caráter social, pois o público pode questionar, retificar e ampliar o que sabe, bem como entender algo nunca aprendido ou nunca percebido. Desse modo, o conhecimento partilhado nas Feiras de Ciências alcança não somente os estudantes, mas a sociedade, revelando, assim, a sua dimensão política.

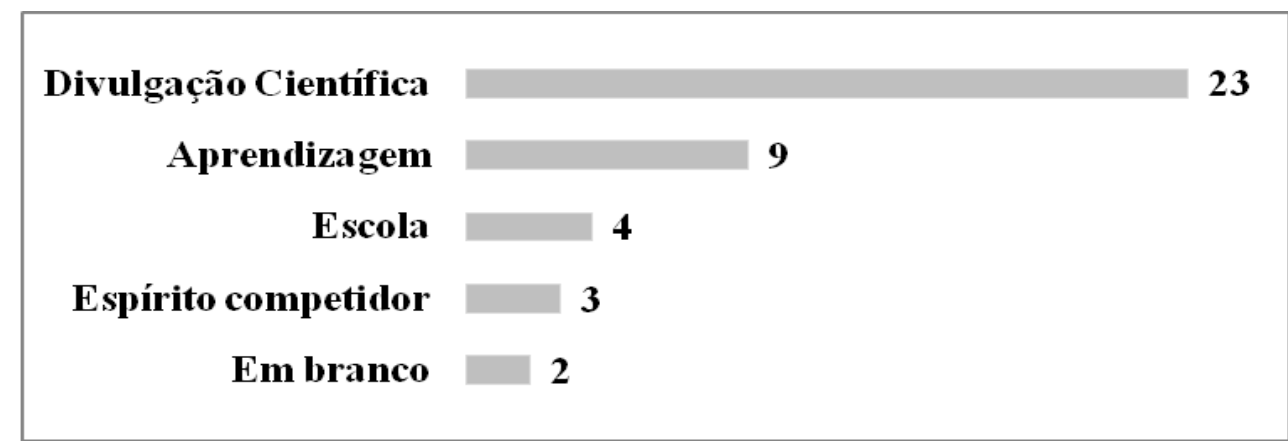

Figura 2 - Motivo para a inscrição na FECEAL 2019

Fonte: Pesquisa dos autores.

Outra resposta que merece análise é a de $\mathrm{P} 12$, “O projeto foi fundamental para o início da minha vida científica.", indicando a contribuição dos projetos de Ciências para impulsionar a carreira científica de estudantes da Educação Básica, conforme declara Santos (2012). A participação na Feira de Ciências, portanto, pode contribuir não somente para a aprendizagem de conteúdos pelos estudantes, mas para ampliar o seu desejo de compreendê-los melhor, influenciando a sua escolha de curso na Educação Superior. 
Houve também 9 (nove) respostas relacionadas com a aprendizagem, principalmente de Ciências, conforme declarou P20: "Porque é uma forma de termos mais conhecimento científico.”. A participação em projetos de Ciências favorece o aprofundamento do conteúdo, tal como declara Reis (2018, p. 131): “[...] a divulgação científica realiza duas funções que se completam: em primeiro lugar, a função de ensinar, suprindo ou ampliando a função da própria escola; em segundo lugar, a função de fomentar o ensino.".

Ainda na $2^{\mathrm{a}}$ questão, quatro respostas afirmaram que a escola/direção/professor os incentivaram a se inscreverem no evento, evidenciando o papel que a escola e os professores têm de proporcionar para os estudantes experiências significativas, inclusive quando esses solicitam "[...] de seu professor a continuidade do trabalho, como maneira de atender a forma natural de aprender." (NEVES; GONÇALVES, 1989, p. 241).

Ao serem questionados sobre como foi a escolha do tema do projeto de Ciências, 12 (doze) estudantes (Figura 3) alegaram o fato de ser um tema importante, podendo ser ou não da sua região, como elucidado no comentário de P2: "Buscamos algo que envolvesse a comunidade, para que através desse tema fosse possível ter melhorias na qualidade de vida e promoção da saúde.”, estando alinhado com as respostas dos demais.

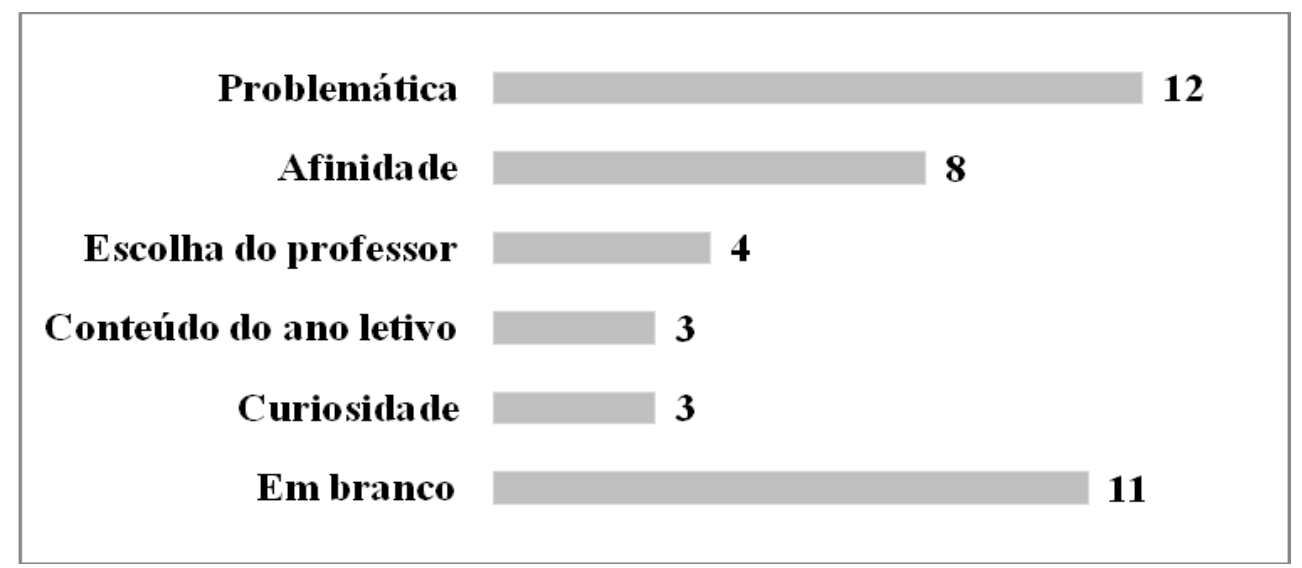

Figura 3 - Critérios para a escolha do tema dos trabalhos apresentados na FECEAL 2019 Fonte: Pesquisa dos autores.

Corroborando com esse fato, Neves e Gonçalves (1989, p. 241) afirmam que “[...] são muitos os problemas existentes em uma comunidade que, uma vez observados, podem se constituir em projetos e trabalhos verdadeiramente inéditos.”. Quando as escolas produzem projetos de Ciências, que podem melhorar a sociedade do entorno, mesmo que não sejam da área de Ciências da Natureza, elas se aproximam da sociedade, pois essa atribui relevância à Educação. A diversidade de temas foi constatada nos trabalhos da FECEAL 2019. 
Ressaltamos que 4 (quatro) participantes afirmaram que foi o docente quem escolheu o tema, conforme exposto por P24: "Foi uma escolha da professora, mas achamos importante.". Houve também temas que foram debatidos pelos estudantes e votaram democraticamente o que iriam desenvolver, conforme a resposta do P38: "Foi uma escolha coletiva visando os melhores benefícios e foi escolhido por todos nós e por apresentar só prós.”.

A escolha do tema a ser investigado é muito importante, pois ele está relacionado ao envolvimento discente e incentiva a sua "[...] curiosidade científica e inovadora." (CABRAL; BARROSO, 2020, p. 12). Destacamos, ainda, a relevância da pergunta, da elaboração de objetivos e de hipóteses, da escolha metodológica, da coleta de dados e da análise desses.

Ao serem questionados sobre o espaço utilizado para fazer o projeto de Ciências, houve uma diversidade de respostas, mas a Sala de aula foi a mais selecionada, seguida do Laboratório de Ciências, do Campo e da Casa (Figura 4).

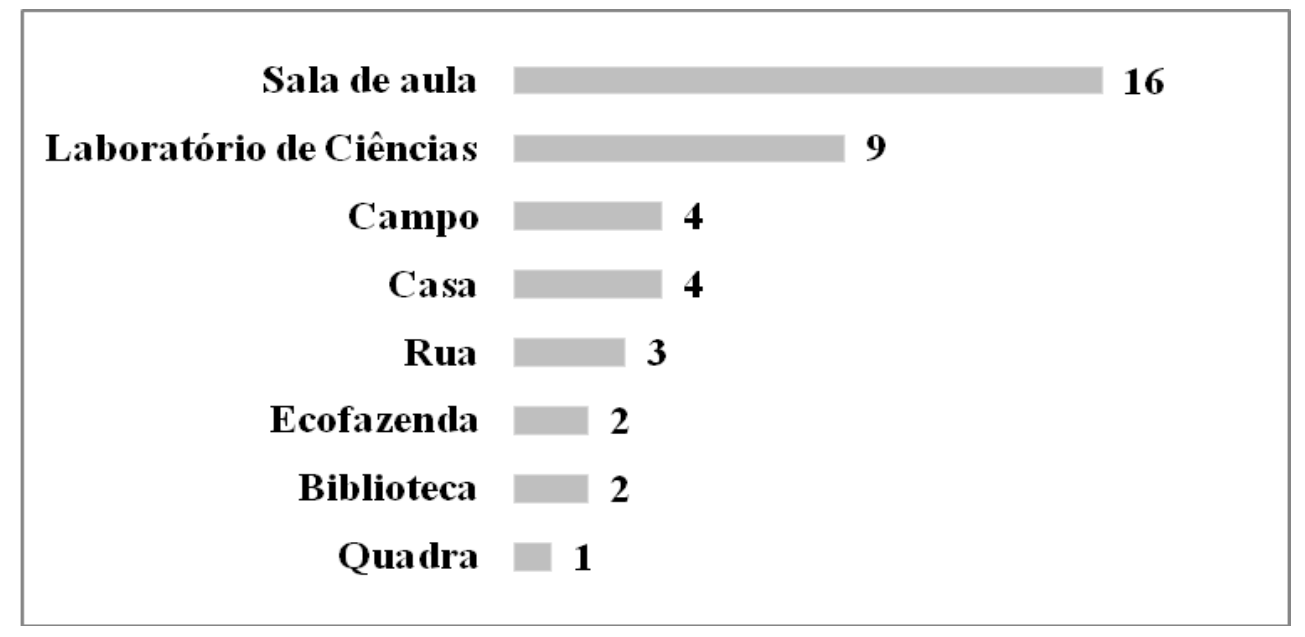

Figura 4 - Locais em que foram realizados os trabalhos apresentados na FECEAL 2019 Fonte: Pesquisa dos autores.

Era esperado que os Laboratórios de Ciências fossem o espaço mais utilizado, considerando que esse é um dos objetivos da FECEAL. Esse dado, contudo, precisa ser relativizado, considerando que os trabalhos apresentados na FECEAL 2019 não se restringiram à área de Ciências da Natureza, conforme postulam Neves e Gonçalves (1989).

Dos 8 (oito) locais, 4 (quatro) são na escola e 4 (quatro) fora dela. Foram desenvolvidos 28 (vinte e oito) trabalhos na escola e 13 (treze) fora dela. Dos realizados na escola, 16 (dezesseis) foram na sala de aula e apenas 9 (nove) no Laboratório de Ciências, o que pode indicar a ausência desse espaço ou a precariedade do mesmo, conforme Weber (2016). A 
realização de trabalhos fora da escola provavelmente está relacionada com a busca de solução para problemas da sociedade, conforme citado por alguns participantes.

A quinta questão, de natureza aberta, abordava a metodologia e a ocorrência de alterações. Quase a metade dos estudantes, 19 (dezenove), não informou a metodologia de seus trabalhos, que pode ter várias interpretações: não compreensão da pergunta, pouca participação no projeto de Ciências ou a repetição da demonstração realizada pelo professor. Essa significativa quantidade de respostas nos impele a indagar como está sendo desenvolvida a iniciação científica desses estudantes, pois esse aspecto é central na formação científica.

Dos 22 (vinte e dois) estudantes que nomearam a metodologia, a Pesquisa laboratorial, a Pesquisa bibliográfica e a Proposta de conscientização foram as mais citadas (Figura 5).

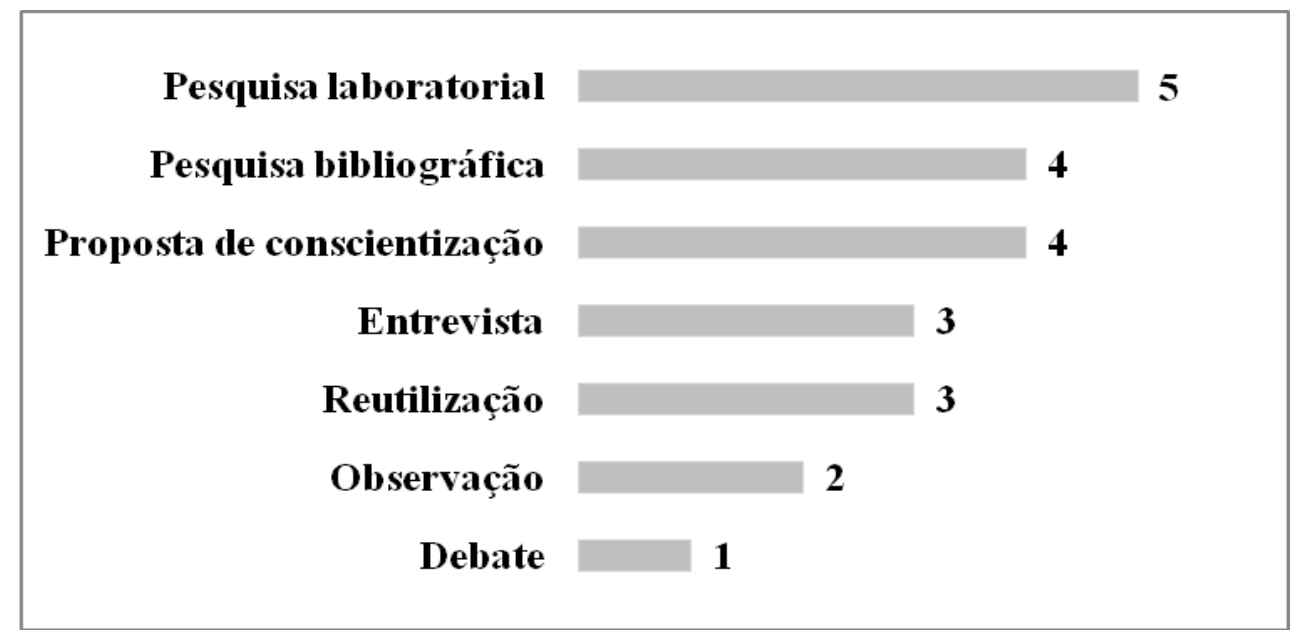

Figura 5 - Tipos de metodologias dos trabalhos apresentados na FECEAL 2019 Fonte: Pesquisa dos autores.

Esse resultado mostra a diversidade de metodologias citadas nas falas dos estudantes, que podem ser desenvolvidos os projetos para Feiras de Ciências, incentivando assim o desenvolvimento da Educação Científica nas escolas. As respostas de P04 - "Criamos cartilhas e através de um trabalho de campo conscientizamos os moradores sobre os agraves à saúde pela falta do saneamento básico e passamos informações sobre as principais doenças e as medidas de controle." - e P33 - "Fizemos reuso de materiais descartáveis." - representam essa diversidade, que explicita o fato de que a Ciência é produzida em todo lugar e não apenas em laboratórios, bem como que a Feira de Ciências avança também para o campo social.

No entendimento de Rosa (1995), é responsabilidade do professor, considerando os problemas que serão investigados, indicar a metodologia adequada. Pavão e Lima (2019), por sua vez, postulam que professor e estudantes são parceiros na definição de um projeto de 
Ciências, os quais, depois de escolherem a temática, precisam definir o caminho, as estratégias para implementá-lo.

Considerando os dados coletados na FECEAL, as contribuições teóricas e a nossa experiência acadêmica e profissional, indagamos se os estudantes participantes estão aprendendo ou somente reproduzindo experimentos, sem refletir sobre o que estão fazendo. Para que os resultados sejam mais positivos, é necessário que o protagonismo estudantil na pesquisa seja maximizado.

Sempre que possível, o professor precisa assumir o papel de orientador e propiciar que os discentes participem de todas as etapas da pesquisa, para que possam compreender a natureza da Ciência e a sua pesquisa. Indicamos, portanto, a necessidade de que os professores sejam orientados para que desenvolvam projetos de Ciências que favoreçam a aprendizagem discente e não apenas a participação em uma Feira de Ciências.

Em relação às iniciativas que estabelecem a interação entre Ciência e Educação, em prol da divulgação científica, Pavão e Lima (2019, p. 05) assinalam o papel “[...] do professor para a promoção de atividades de investigação científica e daí destacam a necessidade de formação continuada de professores.".

Quando questionados se houve alterações durante o desenvolvimento do projeto de Ciências, 8 (oito) estudantes afirmaram que sim, porém poucos conseguiram explicar a ocorrências daquelas, excetuando P13 - "Foi feita uma pesquisa em livros, revistas e na internet. A mudança ocorrida foi a realização de um difusor de ambiente que não estava no projeto, mas decidimos tentar fazer." - e P17 - "Devido aos resultados dos testes não surtirem o efeito desejado, alteramos várias vezes.”.

Houve também metodologias do tipo "receita de bolo", metaforicamente, pois alguns estudantes narraram como fazer em passos, repetindo a metodologia de outro trabalho, como a resposta de P22: "Primeiro preparamos a farinha da casca de manga, depois tentamos fazer o brownie com ela substituindo a farinha normal pela nossa e pedimos para as pessoas experimentarem e responder o questionário se gostaram ou não.”.

Infelizmente, a concepção tradicional de ensino, a qual acredita que o conhecimento é algo pronto e pode ser transmitido aos estudantes, mediante a reprodução/repetição, ainda acontece na escola e nas Feiras de Ciências (FARIAS; GONÇALVES, 2007).

Quando indagados se os objetivos foram alcançados, 27 (vinte e sete) estudantes responderam que sim (Figura 6). 


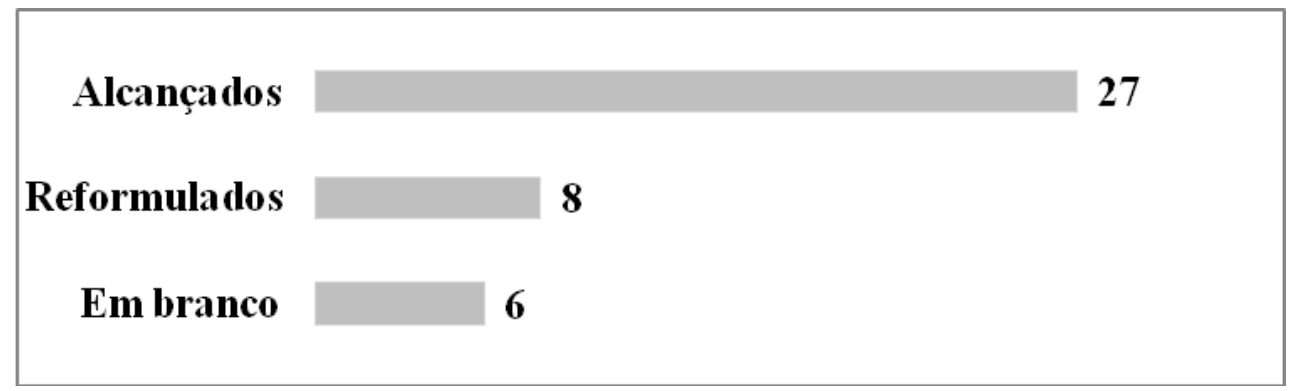

Figura 6 - Alcance dos objetivos dos trabalhos apresentados na FECEAL 2019

Fonte: Pesquisa dos autores.

No entanto, 8 (oito) participantes afirmaram que seus objetivos foram alterados de acordo com o resultado obtido. A resposta de P31 elucidada esse fato: "Nossos objetivos foram reformulados porque o resultado que a gente teve foi diferente do que a professora achava que ia ser, tivemos que ampliar.".

Apesar de ser comum a alteração nos objetivos, indagamos se esses estudantes sabem que uma pesquisa vai além do resultado, pois considera a trajetória percorrida e o conhecimento construído. Desse modo, é imprescindível que esses sujeitos compreendam e aceitem a natureza das Ciências, para que não fiquem reféns e até desanimem da pesquisa quando não encontrarem um resultado esperado ou a confirmação de uma hipótese.

$\mathrm{Na}$ sétima questão, de natureza fechada, o estudante informava a fonte de auxílio que recebeu durante o projeto, sendo possível indicar mais de uma. Dos 41 (quarenta e um) estudantes, 39 (trinta e nove) elegeram o professor. Ou seja, quase a totalidade dos entrevistados indica a importância do docente na realização do projeto de Ciências! As demais respostas registraram a Coordenação, os Pais e a Universidade (Figura 7).

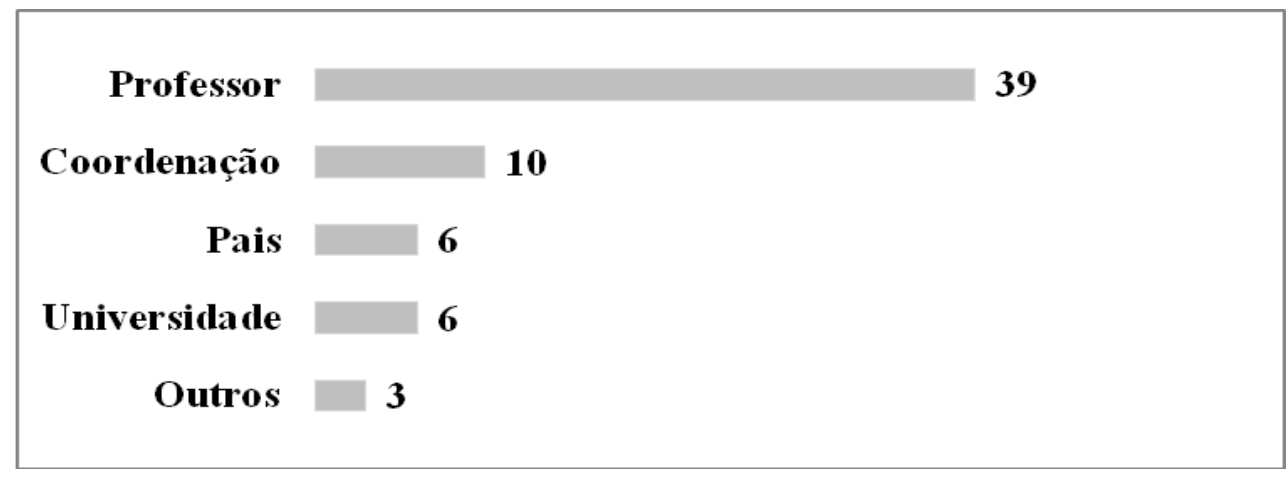

Figura 7 - Fonte de auxílio recebido dos trabalhos apresentados na FECEAL 2019 Fonte: Pesquisa dos autores.

Em relação às 6 (seis) citações da Universidade, o apoio ocorreu mediante o Programa Institucional de Bolsas de Iniciação à Docência - PIBID. O estado de Alagoas foi habilitado 
com 959 (noventa e cinquenta e nove) bolsas do PIBID para discentes dos cursos de Licenciatura das seguintes Instituições de Educação Superior - IES: a Universidade Federal de Alagoas, o Centro de Estudos Superiores de Maceió, o Instituto Federal de Alagoas, a Faculdade de Tecnologia de Alagoas e a Universidade Estadual de Alagoas (BRASIL, 2018).

Considerando o total de bolsas aprovadas (959) e a quantidade de bolsistas de cada subprojeto por escola (8), a quantidade máxima de escolas contempladas pelas ações do PIBID é 120 (cento e vinte). Contactamos, via WhatsApp, os 5 (cinco) coordenadores institucionais do PIBID das IES citadas, e estimamos, a partir das informações deles, que aproximadamente 100 (cem) escolas públicas de Alagoas foram beneficiadas com ele.

O estado de Alagoas, conforme dados do Censo Escolar de 2018, possui 2.481 escolas públicas de Educação Básica. Concluímos, portanto, que, no máximo, apenas 4,03\% dessas escolas acolheram ações desenvolvidas pelo PIBID, uma vez que é possível uma escola ter mais de um subprojeto de áreas distintas.

Diante desse contexto, as 6 (seis) menções à Universidade podem indicar que o PIBID, além de contribuir para melhorar a qualidade das atividades pedagógicas desenvolvidas pelos professores da Educação Básica e enriquecer a formação inicial dos licenciandos, está colaborando para o desenvolvimento de projetos de Ciências.

O fortalecimento do PIBID propiciará a ampliação da colaboração nas situações relatadas, as quais são ratificadas por Castro, Araújo e Oliveira (2019, p. 180), quando declaram que as Feiras de Ciências “[...] possibilitam promover aprendizagens integradas, a aproximação interinstitucional e fortalecimento de processos e de práticas de formação científica dos professores e de estudantes da Educação Básica.”.

Em relação a essa aproximação entre as instituições educacionais, é importante destacar que a FECEAL 2019 teve o apoio do Conselho Nacional de Desenvolvimento Científico e Tecnológico - CNPq e os seguintes parceiros: “[...] a Universidade Federal de Alagoas - UFAL, Instituto Federal de Alagoas - IFAL, Universidade de Ciências da Saúde de Alagoas UNCISAL, Laboratório Central do Estado de Alagoas - LACEN, Universidade Tiradentes UNIT entre outros.”. (ALAGOAS, 2019, p. 01).

Considerando os dados colhidos, compreendemos que as Feiras de Ciências, enquanto expressão pedagógica e cultural, efetivamente possuem

[...] elevado potencial motivador do ensino e da prática científica no ambiente escolar. Tanto para alunos e professores, quanto para a comunidade em geral, as feiras vêm constituindo uma oportunidade de aprendizagem e de entendimento sobre as etapas de construção do conhecimento científico. (BRASIL, 2006, p. 05). 
Essa constatação não nos impede de reconhecer os limites dos trabalhos apresentados na FECEAL 2019, de modo especial, no tipo de trabalho e na metodologia. Esses aspectos se configuram como desafios para a melhoria das próximas edições das FECEAL, o que irá demandar compromisso de todos os agentes pedagógicos, de modo especial, da Secretaria de Educação e dos gestores escolares para ampliar o apoio para docentes e estudantes.

\section{CONSIDERAÇÕES FINAIS}

Os trabalhos apresentados na Feira de Ciências do Estado de Alagoas (FECEAL), em 2019, contemplaram diversas áreas do conhecimento e foram além de apenas propor objetivo, metodologia, resultados e conclusões, pois eles contribuíram tanto para o estudante, na sua formação científica, como para a sociedade, divulgando, um pouco, o que é produzido nas escolas públicas alagoanas.

Nesta pesquisa, constatamos a utilização de diversos espaços da escola, como também de ambientes fora dela, indicando que o projeto de Ciências não ficou retido aos saberes do ano letivo, contemplando problemas que os estudantes/pesquisadores buscaram solucionar nas suas pesquisas. Em virtude disso, podemos afirmar que o projeto de Ciências não requer, de modo geral, grandes infraestruturas e equipamentos sofisticados e caros, sendo possível realizá-lo nas escolas públicas.

As respostas colhidas ressaltaram a importância da participação dos estudantes em Feiras de Ciências, seja porque é uma forma peculiar de ensinar e aprender, para aqueles e os professores, seja porque divulga o conhecimento científico na sociedade, popularizando-o via Educação não-formal. Imprescindível, portanto, o incentivo para desenvolver mais projetos de Ciências na Educação Básica, além do fortalecimento do PIBID e dos vínculos interinstitucionais.

Ratificamos que a Feira de Ciência pode favorecer a produção e divulgação científica, melhorando a aprendizagem discente, o relacionamento entre professor e estudante, bem como o vínculo entre escola e sociedade. Para que esses frutos ocorram, são necessárias mudanças dentro e fora da escola, com foco nas condições de trabalho docente, na formação continuada e na estrutura material, sendo necessário o apoio dos órgãos competentes.

Sugerimos a realização de estudos com foco em outros aspectos das Feiras de Ciências não contemplados nessa pesquisa: os professores orientadores e o público, bem como a 
avaliação dos trabalhos e da sua apresentação. Pensamos também ser interessante investigar os acontecimentos que antecedem as Feiras de Ciências nas escolas, bem como averiguar se os trabalhos nela apresentados possuem continuidade.

\section{REFERÊNCIAS}

ALAGOAS. Secretaria da Educação do Estado de Alagoas. Regulamento da Feira de Ciências do Estado de Alagoas - FECEAL/Edição 2016. Maceió, 2016. Disponível em: https://drive.google.com/file/d/0B1d_ytyPzixnYTlsZ201eFlIOUE/view. Acesso em: 05 jan. 2021.

ALAGOAS. Secretaria da Educação do Estado de Alagoas. Regulamento da Feira de Ciências do Estado de Alagoas - FECEAL 2019/CNPq. Maceió, 2019. Disponível em: https://drive.google.com/file/d/1nAgfKBPFAqghJfMgru3DXemIDL38IcDi/view. Acesso em: 05 jan. 2021.

BAGNO, M. Pesquisa na escola: o que é, como se faz. São Paulo: Editora Loyola, 1998.

BRASIL. Ministério da Educação. Coordenação de Aperfeiçoamento de Pessoal de Nível Superior. Programa Institucional de Bolsas de Iniciação à Docência - PIBID: resultado final das instituições habilitadas e cotas aprovadas, 2018. Disponível em:

https://www.gov.br/capes/pt-br/centrais-de-conteudo/29052018-resultado-final-e-cotasaprovadas-pibid-pdf/@@download/file/29052018-resultado-final-e-cotas-aprovadaspibid.pdf. Acesso em: 30 set. 2020.

BRASIL. Ministério da Educação. Secretaria de Educação Básica. Programa Nacional de Apoio às Feiras de Ciências da Educação Básica Fenaceb. Brasília: MEC/ SEB, 2006. Disponível em: http://portal.mec.gov.br/seb/arquivos/pdf/EnsMed/fenaceb.pdf. Acesso em: 30 set. 2020 .

CABRAL, A. M. O.; BARROSO, M. C. S. Mostra científica: caminho para a alfabetização científica nas escolas municipais de Maracanaú. Research, Society And Development, Itabira, v. 9, n. 2, 2020. Disponível em: https://rsd.unifei.edu.br/index.php/rsd/article/viewFile/2036/1678. Acesso em: 30 set. 2020.

CASTRO, C. S. de; ARAÚJO, I. A. F. de; OLIVEIRA, R. C. Formação continuada no âmbito da I FECITBA: análise da experiência desenvolvida em Óbidos-Baixo Amazonas-PA.

REAMEC - Rede Amazônica de Educação em Ciências e Matemática, Cuiabá, v. 7, n. 3, p. 176-192, 2019. Disponível em:

https://periodicoscientificos.ufmt.br/ojs/index.php/reamec/article/view/9275. Acesso em: 30 set. 2020.

CORSINI, A. M. A.; ARAÚJO, E. S. N. N de. Feira de Ciências como espaço não formal de ensino: um estudo com alunos e professores do Ensino Fundamental. In: VI Encontro

Nacional de Pesquisa em Educação em Ciências. Anais do VI ENPEC - Encontro Nacional de Pesquisa em Educação em Ciências, 2007. Disponível em:

http://www.nutes.ufrj.br/abrapec/vienpec/apresenta0.html. Acesso em: 30 set. 2020. 
COSTA, L. D.; ROEHRS, M. M.; DESTRO, V. C.; GIMENEZ, R. F.; MELLO, G. J. Uso da Feira de Ciências como metodologia estratégica para iniciação científica de estudantes da Educação Básica. In: V Congresso Nacional de Educação. Anais do V CONEDU - V Congresso Nacional de Educação, 2018.

FALCÃO SOBRINHO, J.; FALCÃO, C. L. da C.; ALMEIDA, E. F. de.. Feira de Ciências e mostras científicas: uma iniciação à pesquisa científica. Revista Essentia, Sobral, v. 15, n. 2, p. 109-130, dez. 2013/maio 2014. Disponível em:

https://essentia.uvanet.br/index.php/ESSENTIA/article/view/55. Acesso em: 30 set. 2020.

FARIAS, L. N.; GONÇALVES, T. V. O. Feira de Ciências como espaço de formação e desenvolvimento de professores e alunos. AMAZÔNIA - Revista de Educação em Ciências e Matemáticas, Belém, v. 3, n. 6, p. 25-33, 2007. Disponível em:

https://periodicos.ufpa.br/index.php/revistaamazonia/article/view/1729. Acesso em: 30 set. 2020.

GASPAR, A. A educação formal e a educação informal em Ciências. In: MASSARANI, L.; MOREIRA, I. de C.; BRITO, F. (Org.). Ciência e público - caminhos da divulgação científica no Brasil. Rio de Janeiro: Editora da UFRJ, 2002. p. 171-183.

GIL, A. C. Métodos e técnicas de pesquisa social. 5. ed. São Paulo: Atlas, 1999.

LÜDKE, M.; ANDRÉ, M. E. D. A. Pesquisa em Educação: abordagens qualitativas. São Paulo: Editora EPU, 1986.

MACHADO, S. S.; BLANCO, A. J. V.; BARROS, V. F. A.; CARDOSO, E. B. A Feira de Ciências como ferramenta educacional para formação de futuros pesquisadores. In: Congreso Iberoamericano de Ciencia, Tecnología, Innovación y Educación, 2014, Buenos Aires. Anais... Buenos Aires, 2014. Disponível em: https://www.oei.es/historico/congreso2014/memoriactei/1204.pdf. Acesso em: 30 set. 2020.

MANCUSO, R. Feiras de Ciências: produção estudantil, avaliação, consequências. Contexto Educativo: Revista digital de Educación y Nuevas Tecnologias, Buenos Aires, n. 6, abr. 2000. Disponível em:

http://www.redepoc.com/jovensinovadores/FeirasdeCienciasproducaoestudantil.htm. Acesso em: 30 set. 2020.

MANCUSO, R. Feiras de Ciências, das escolares às nacionais: conflitos e sucessos. In: Reunião Regional da Sociedade Brasileira para o progresso da Ciência, 2, 2006, Porto Alegre. Anais... Porto Alegre, 2006. 1 CD- ROM.

MONTES, M. A. de A.; SOUZA, C. T. V. de. Atuação de alunos universitários em espaço não formal de ensino: estratégia motivadora e integradora para o desenvolvimento de atividades práticas e assistenciais. Alexandria: Revista de Educação em Ciência e Tecnologia, Florianópolis, v. 1, n. 2, p. 63-79, jul. 2008. Disponível em: https://periodicos.ufsc.br/index.php/alexandria/article/view/37492/28787. Acesso em: 30 set. 2020.

MORAES, R. Debatendo o ensino de Ciências e as Feiras de Ciências. Boletim Técnico do PROCIRS, Porto Alegre, v. 2, n. 5, p. 18-20, 1986. 
NEVES, S. R. G.; GONÇALVES, T. V. O. Feiras de Ciências. Cad. Cat. Ens. Fís., Florianópolis, v. 6, n. 3, p. 241-247, dez. 1989. Disponível em:

https://periodicos.ufsc.br/index.php/fisica/article/view/9257/15165. Acesso em: 30 set. 2020.

PAVÃO, A. C.; LIMA, M. E. C. Feiras de Ciência, a revolução científica na escola. Revista Brasileira de Pós-Graduação, Brasília, v. 15, n. 34, p. 1-11, nov. 2019. Disponível em: http://ojs.rbpg.capes.gov.br/index.php/rbpg/article/view/1612/887. Acesso em: 30 set. 2020.

PEREIRA, A. B.; OAIGEN, E. R.; HENNIG, G. Feiras de Ciências. Canoas: Ulbra, 2000.

RAMOS, M. G.; LIMA, V. M. do R.; ROCHA FILHO, J. B. da. A pesquisa como prática na sala de aula de ciências e matemática: um olhar sobre dissertações. Alexandria: Revista de Educação em Ciência e Tecnologia, Florianópolis, v. 2, n. 3, p. 53-81, nov. 2009.

Disponível em:

https://periodicos.ufsc.br/index.php/alexandria/article/view/37994/28995. Acesso em: 30 set. 2020.

REIS, J. Feiras de ciência: uma revolução pedagógica. In: MASSARANI, L.; DIAS, E. M. de S. (Org.). José Reis: reflexões sobre a divulgação científica. Rio de Janeiro: Fiocruz/COC, 2018.

ROSA, P. R. da S. Algumas questões relativas a Feiras de Ciências: para que servem e como devem ser organizadas. Caderno Brasileiro de Ensino de Física, Florianópolis, v. 12, n. 3, p. 223-228, dez. 1995. Disponível em:

https://periodicos.ufsc.br/index.php/fisica/article/view/7086/6557. Acesso em: 30 set. 2020.

SANTOS, A. B. Feiras de Ciência: um incentivo para desenvolvimento da cultura científica.

Rev. Ciênc. Ext., São Paulo, v. 8, n. 2, p. 155-166, 2012. Disponível em:

https://ojs.unesp.br/index.php/revista_proex/article/view/717. Acesso em: 30 set. 2020.

SEVERINO, A. J. Metodologia do trabalho científico. São Paulo: Cortez, 2016.

STROHSCHOEN, A. A. G.; PUHL, C. D.; MARCHI, M. I. Feiras de Ciências: formando os cientistas do futuro - Ensino Fundamental. Revista Destaques Acadêmicos, Lajeado, v. 5, n. 5, p. 43-48, 2013. Disponível em:

http://www.meep.univates.br/revistas/index.php/destaques/article/view/362/356. Acesso em: 30 set. 2020 .

TRIVIÑOS, A. N. S. Introdução à pesquisa em Ciências Sociais: a pesquisa qualitativa em Educação - o Positivismo, a Fenomenologia, o Marxismo. São Paulo: Atlas, 1987.

VIEIRA; V.; BIANCONI, M. L.; DIAS, M. Espaços Não-Formais de ensino e o currículo de Ciências. Ciência e Cultura, São Paulo, v. 57, n. 4, p. 21-23, out./dez. 2005. Disponível em: http://cienciaecultura.bvs.br/pdf/cic/v57n4/a14v57n4.pdf. Acesso em: 07 jan. 2021.

WEBER, F. S. D. As Feiras de Ciências escolares: um incentivo à pesquisa. Scientia Cum Industria, Caxias do Sul, v. 4, n. 4, p. 188-190, 2016. Disponível em:

http://www.ucs.br/etc/revistas/index.php/scientiacumindustria/article/view/4890/pdf. Acesso em: 30 set. 2020. 


\section{NOTAS}

\section{AGRADECIMENTOS}

Não se aplica.

\section{FINANCIAMENTO}

Não se aplica.

\section{CONTRIBUIÇÕES DE AUTORIA}

Resumo/Abstract/Resumen: Bibiane de Fátima Santos, Maria Danielle Araújo Mota e Paulo Meireles Barguil Introdução: Bibiane de Fátima Santos, Maria Danielle Araújo Mota e Paulo Meireles Barguil Referencial teórico: Bibiane de Fátima Santos, Maria Danielle Araújo Mota e Paulo Meireles Barguil Análise de dados: Bibiane de Fátima Santos, Maria Danielle Araújo Mota e Paulo Meireles Barguil Discussão dos resultados: Bibiane de Fátima Santos, Maria Danielle Araújo Mota e Paulo Meireles Barguil Conclusão e considerações finais: Bibiane de Fátima Santos, Maria Danielle Araújo Mota e Paulo Meireles Barguil Referências: Bibiane de Fátima Santos, Maria Danielle Araújo Mota e Paulo Meireles Barguil Revisão do manuscrito: Bibiane de Fátima Santos, Maria Danielle Araújo Mota e Paulo Meireles Barguil Aprovação da versão final publicada: Bibiane de Fátima Santos, Maria Danielle Araújo Mota e Paulo Meireles Barguil

\section{CONFLITOS DE INTERESSE}

Os autores declararam não haver nenhum conflito de interesse de ordem pessoal, comercial, acadêmico, político e financeiro referente a este manuscrito.

DISPONIBILIDADE DE DADOS DE PESQUISA

O conjunto de dados que dá suporte aos resultados da pesquisa foi publicado no próprio artigo.

\section{CONSENTIMENTO DE USO DE IMAGEM}

Não se aplica.

\section{APROVAÇÃO DE COMITÊ DE ÉTICA EM PESQUISA \\ Não se aplica.}

\section{COMO CITAR - ABNT}

SANTOS, Bibiane de Fátima; MOTA, Maria Danielle Araújo; BARGUIL, Paulo Meireles. Feira de Ciências do Estado de Alagoas: Conquistas e desafios no desenvolvimento dos trabalhos. REAMEC - Rede Amazônica de Educação em Ciências e Matemática. Cuiabá, v. 9, n. 1, e21008, janeiro-abril, 2021. DOI: 10.26571/reamec.v9i1.11408.

\section{COMO CITAR - APA}

SANTOS, B. F.; M, M. D. A. \& BARGUIL, P. M. (2021). Feira de Ciências do Estado de Alagoas: Conquistas e desafios no desenvolvimento dos trabalhos. REAMEC - Rede Amazônica de Educação em Ciências e Matemática, 9 (1), e21008. DOI: 10.26571/reamec.v9i1.11408.

\section{LICENÇA DE USO}

Licenciado sob a Licença Creative Commons Attribution-NonCommercial 4.0 International (CC BY-NC 4.0). Esta licença permite compartilhar, copiar, redistibuir o manuscrito em qualquer meio ou formato. Além disso, permite adaptar, remixar, transformar e construir sobre o material, desde que seja atribuído o devido crédito de autoria e publicação inicial neste periódico.

\section{DIREITOS AUTORAIS}

Os direitos autorais são mantidos pelos autores, os quais concedem à Revista REAMEC - Rede Amazônica de Educação em Ciências e Matemática - os direitos exclusivos de primeira publicação. Os autores não serão remunerados pela publicação de trabalhos neste periódico. Os autores têm autorização para assumir contratos adicionais separadamente, para distribuição não exclusiva da versão do trabalho publicada neste periódico (ex.: publicar em repositório institucional, em site pessoal, publicar uma tradução, ou como capítulo de livro), 
com reconhecimento de autoria e publicação inicial neste periódico. Os editores da Revista têm o direito de proceder a ajustes textuais e de adequação às normas da publicação.

\section{PUBLISHER}

Universidade Federal de Mato Grosso. Programa de Pós-graduação em Educação em Ciências e Matemática (PPGECEM) da Rede Amazônica de Educação em Ciências e Matemática (REAMEC). Publicação no Portal de Periódicos UFMT. As ideias expressadas neste artigo são de responsabilidade de seus autores, não representando, necessariamente, a opinião dos editores ou da referida universidade.

\section{EDITOR}

Marcel Thiago Damasceno Ribeiro

\section{HISTÓRICO}

Submetido: 09 de novembro de 2020.

Aprovado: 17 de dezembro de 2020.

Publicado: 22 de janeiro de 2021. 